\title{
PRODUKSI BIOETANOL DARI BIJI BUAH NANGKA (Artocarpus heterophyllus) MELALUI PROSES HIDROLISIS ASAM SULFAT DAN FERMENTASI
}

\author{
Tadjuddin Naid "), Muzakkir Baits ${ }^{* *}$, Yenni Triana ${ }^{* *}$ \\ ${ }^{*}$ Fakultas Farmasi, Universitas Hasanuddin \\ ${ }^{* *}$ Fakultas Farmasi, Universitas Muslim Indonesia \\ Email : tadjuddinnaid@yahoo.co.id
}

\begin{abstract}
Fermentation from jackfruit seeds (Artocarpus heterophyllus) through the Process Using Acid Hydrolysis. Bioethanol is ethanol fermentation process biomass results with the help of microorganisms. Raw materials for bioethanol is sugary materials, starchy and fibrous. This study tries to make bioethanol from jackfruit seeds (Artocarpus heterophyllus) which is a starchy material. during these jackfruit seeds into consumption only partly public and partly not used. The purpose of this study was to determine the optimum concentration of $\mathrm{H}_{2} \mathrm{SO}_{4}$ on the hydrolysis process and determine the optimum fermentation time in the fermentation process. The process of making ethanol in two steps, namely acid hydrolysis and fermentation. Cassava peel hydrolyzed by using a solution of $\mathrm{H}_{2} \mathrm{SO}_{4}$ in a variety of variable concentrations $(0.1,0.5$ and $1 \mathrm{M})$ at a temperature of $100^{\circ} \mathrm{C}$ for 1 hour. Then a solution of the hydrolysis fermented with various variables days $(1,2,3,4,5$, 6 and 7 days). The result showed that the optimum concentration of $\mathrm{H}_{2} \mathrm{SO}_{4}$ solution for the hydrolysis reaction is $1 \mathrm{M}$ at a temperature of $100^{\circ} \mathrm{C}$ for 1 hour and the optimum fermentation time in the fermentation process is on day 4 where the produced ethanol at $13,19 \% \mathrm{v} / \mathrm{v}$.
\end{abstract}

Key words : Fermentation, Artocarpus heterophyllus, Hydrolysis

\section{PENDAHULUAN}

Nangka merupakan tanaman yang sudah tidak asing lagi bagi masyarakat di Indonesia. Nangka adalah salah satu jenis buah yang paling banyak ditanam di daerah tropis. Buah ini cukup terkenal di seluruh dunia, apalagi di pedesaan.

Di Indonesia untuk mendapatkan biji nangka tidaklah sulit karena pohon nangka hampir tumbuh di setiap daerah dan merupakan tumbuhan tahunan. Selain itu biji nangka merupakan buah nangka yang masih jarang dimanfaatkan masyarakat, maka untuk mendapatkannya relatif mudah.

Selama ini biji buah nangka dimanfaatkan sebagai tepung yang digunakan sebagai bahan baku industri makanan (bahan makan campuran) dan sebagian masyarakat 
Produksi Bioetanol Dari Biji Buah Nangka Melalui Proses Hidrolisis Asam Sulfat Dan Fermentasi

memanfaatkan dengan cara menkonsumsi. Sehingga biji buah nangka yang tadinya belum dimanfaatkan dapat diubah menjadi produk yang bernilai ekonomis.

Kandungan serat pada biji nangka tinggi yaitu sekitar $36,7 \%$, Pembuatan bioetanol dari buah biji nangka melalui dua tahap yaitu proses hidrolisis asam yang kemudian dilanjutkan dengan proses fermentasi. Proses hidrolisis dilakukan untuk mengubah selulosa dari biji nangka menjadi glukosa. Hidrolisis dengan asam akan memutuskan ikatan polisakarida menjadi monosakarida. Fermentasi alkohol merupakan proses aktivitas yeast (Saccharomyces cerevisiae) yang penentuan kadarnya dilanjutkan dengan menggunakan kromatografi gas.

Khamdiyah dalam Hambyah (2010) melakukan penelitian menggunakan rumput laut (alga) merah jenis Euchema spinosum dengan sakarifikasi memperoleh kadar etanol $15,25 \%$ dan tanpa fermentasi memperoleh kadar etanol 6,99\% pada variasi lama fermentasi.

Bioetanol dapat dibuat dari proses pemasakan, fermentasi dan destilasi dari beberapa jenis bahan berpati, bergula dan berselulosa. Bahkan dalam beberapa penelitian bioetenol juga dapat dibuat dari limbah hasil pertanian (biomassa). Manfaat dari bioetenol adalah sebagai campuran bahan obat batuk cair, ekstrak herbal (tumbuh-tumbuhan), parfum, kosmetik, desinfektan, larutan sterilisasi, tinta cetak, spiritus bakar, juga bahan bakar kendaraan yang memperkecil pencemaran udara (bahan bakar ramah lingkungan).

\section{METODOLOGI PENELITIAN}

\section{A. Tempat Penelitian}

Dilaksanakan di Laboratorium Farmasi UMI Makassar dan Laboratorium Kimia Politeknik Makassar

\section{B. Alat dan Bahan Penelitian}

Alat-alat yang digunakan pada penelitian ini adalah seperangkat alat destilasi, alat fermentasi, ayakan, alat ukur indeks bias (refraktometer), blender, batang pengaduk, buret, erlenmeyer 250 ml (Iwaki Pyrex), gelas ukur 100 ml (Iwaki Pyrex), gelas kimia 250 $\mathrm{ml}$ (Iwaki Pyrex), kromatografi gas (GC-2010 shimadzu), pemanas listrik, pisau, sendok stainless steel, timbangan analitik, dan waterbath.

Bahan-bahan yang digunakan pada penelitian ini adalah air suling, aluminium foil, asam sulfat, etanol standar 99,98\% kertas 
Produksi Bioetanol Dari Biji Buah Nangka Melalui Proses Hidrolisis Asam Sulfat Dan Fermentasi

saring, larutan Luff schoorl , Natrium tio sulfat $0,1 \mathrm{~N}$, Ragi (Fermipan) dan serbuk biji buah nangka.

\section{Prosedur Penelitian}

Biji nangka diambil dari buah nangka, kemudian dibersihka $\mathrm{n}$ dan dimemarkan lalu dikeringkan dibawah sinar matahari. Biji nangka kering digiling dengan mesin penggiling (blender) sehingga menjadi serbuk halus.

Serbuk biji nangka diayak sehingga diperoleh hasil yang homogen. Serbuk biji nangka kemudian dihidrolisis dengan menggunakan katalis asam $\left(\mathrm{H}_{2} \mathrm{SO}_{4} \quad 0,1 \quad ; \quad 0,5\right.$ dan $\left.1 \mathrm{M}\right)$ sebanyak 10 gram dalam $100 \mathrm{ml}$ pada suhu $60^{\circ} \mathrm{C}$ selama 30 menit, dengan menggunakan water bath dan dihitung kadar glukosa yang terbentuk.

Ditimbang 15 gram sampel hasil hidrolisis, dimasukkan kedalam labu ukur $100 \mathrm{ml}$ ditambah $\mathrm{Pb}$ asetat $3 \%$ sebanyak $2 \mathrm{ml}$ dan $\mathrm{Na}_{2} \mathrm{CO}_{3} 3 \%$ sebanyak 2 $\mathrm{ml}$, dihimpitkan hingga tanda batas lalu disaring kemudian dipipet $5 \mathrm{ml}$ sampel hasil saringan kedalam erlenmeyer $250 \mathrm{ml}$, ditambahkan $25 \mathrm{ml}$ larutan Luff kemudian dipanaskan selama 10 menit, ditambahkan 2 gram $\mathrm{KI}$ dan 25 $\mathrm{H}_{2} \mathrm{SO}_{4} 4 \mathrm{~N}$ sampai warna larutan berubah menjadi coklat, kemudian dititrasi dengan larutan natrium tio sulfat $\quad 0,1 \quad \mathrm{~N}, \quad$ dengan menggunakan indikator kanji $1 \%$ sampai warnanya menjadi putih susu dan dilakukan titerasi blanko.

Serbuk biji nangka dihidrolisis dengan katalis asam sulfat $\left(\mathrm{H}_{2} \mathrm{SO}_{4}\right)$ dengan konsentrasi gula yang tertinggi dari hasil optimasi konsentrasi hidrolisis kemudian masing-masing suspensi dipanaskan pada suhu $100^{\circ} \mathrm{C}$ selama 30 menit dan 1 jam, kemudian dihitung kadar glukosa yang terbentuk.

Hasil hidrolisis konsentrasi optimum asam sulfat terhadap serbuk biji nangka, ditambahkan $\mathrm{NaOH}$, hingga pH 4 - 6, kemudian ditambahkan ragi komersial (Fermipan) sebanyak 10\% dari volume sampel, dan didiamkan selama 7 hari.

Hasil dari fermentasi yang didapat dimasukkan kedalam labu destilasi, Proses destilasi ini dijalankan pada suhu $70-80^{\circ} \mathrm{C}$, kemudian dianalisis kadar etanolnya.

Konsentrasi etanol ditentukan dengan Gas Kromatografi (GC) 
Produksi Bioetanol Dari Biji Buah Nangka Melalui Proses Hidrolisis Asam Sulfat Dan Fermentasi

pada temperatur $100^{\circ} \mathrm{C}$. Sebelum

sampel diinjeksi ke dalam GC

terlebih dahulu mengukur larutan standar yang akan digunakan sebagai dasar perhitungan konsentrasi etanol.

\section{HASIL PENELITIAN}

Hasil Penelitian mengenai produksi bioetanol dari proses hidrolisis asam dan fermentasi diperoleh data sebagai berikut:

Tabel 1. Hasil analisis kuantitatif Glukosa berbagai variasi konsentrasi asam sulfat pada suhu $60^{\circ} \mathrm{C}$ selama 30 menit.

\begin{tabular}{ccccc}
\hline Sampel & Konsentrasi Asam Sulfat & Berat Sampel (Gram) & Volume Titran(ml) & Kadar \% \\
\hline 1 & $0,1 \mathrm{M}$ & 15,0274 & 13,75 & 1,17 \\
2 & $1,5 \mathrm{M}$ & 15,0132 & 11,40 & 5,35 \\
3 & $1 \mathrm{M}$ & 15,0224 & 3,50 & 7,06 \\
\hline
\end{tabular}

Tabel 2. Hasil analisis kuantitatif glukosa konsentrasi asam sulfat $1 \mathrm{M}$ pada variasi waktu dengan suhu $60^{\circ} \mathrm{C}$.

\begin{tabular}{ccccc}
\hline Sampel $\left(\mathbf{H}_{\mathbf{2}} \mathbf{S O}_{\mathbf{4}}\right) \mathbf{1} \mathbf{M}$ & $\begin{array}{c}\text { Waktu } \\
\text { Hidrolisis }\end{array}$ & $\begin{array}{c}\text { Berat Sampel } \\
(\mathbf{g r a m})\end{array}$ & Volume Titran $(\mathbf{m l})$ & Kadar \% \\
\hline 1 & 30 menit & 15,0121 & 10,30 & 4,61 \\
2 & 60 menit & 15,0035 & 2,85 & 11,67 \\
3 & 90 menit & 15,0126 & 13.2 & 4,72 \\
\hline
\end{tabular}

Tabel 3. Hasil analisis kuantitatif glukosa konsentrasi asam sulfat $1 \mathrm{M}$ pada variasi suhu dengan waktu 60 menit.

\begin{tabular}{ccccc}
\hline Sampel $\left(\mathbf{H}_{\mathbf{2}} \mathbf{S O}_{4}\right) \mathbf{1} \mathbf{M}$ & Suhu hidrolisis & Berat sampel (gram) & volume titran $(\mathbf{m l})$ & Kadar \% \\
\hline 1 & 80 & 15,0048 & 4,50 & 6,71 \\
2 & 100 & 15,0072 & 2,60 & 13,44 \\
3 & 120 & 15,0075 & 13,4 & 3,99 \\
\hline
\end{tabular}

Tabel 4. Nilai indeks bias dari hasil variasi hari fermentasi Biji nangka (Artocarpus heterophyllus).

\begin{tabular}{cc}
\hline Hari & Nilai indeks bias \\
\hline 1 & 1,3382 \\
2 & 1,3386 \\
3 & 1,3391 \\
4 & 1,3412 \\
5 & 1,3409 \\
6 & 1,3406 \\
7 & 1,3397 \\
\hline
\end{tabular}

Tabel 5. Kadar alkohol fermentasi Biji nangka (Artocarpus heterophyllus) pada hari ke 4 dengan kromatografi gas

\begin{tabular}{ccc}
\hline Waktu Fermentasi Hari Ke 4 & Luas Area $\left(\boldsymbol{\mu m}^{2}\right)$ & Berat Dari Pic \\
\hline 4 & 24092554 & 3326225 \\
Standar & 182610940 & 39283780 \\
\hline
\end{tabular}


Produksi Bioetanol Dari Biji Buah Nangka Melalui Proses Hidrolisis Asam Sulfat Dan Fermentasi

\section{PEMBAHASAN}

Bioetanol adalah etanol hasil proses fermentasi biomassa dengan bantuan mikroorganisme. Bahan baku pembuatan bioetanol adalah bahan bergula, berpati dan berserat. Penelitian ini mencoba membuat bioetanol dari biji buah nangka yang merupakan bahan berpati.

Proses hidrolisis dilakukan tiap variabel konsentrasi asam $\mathrm{H}_{2} \mathrm{SO}_{4}(0,1$; 0,5 dan $1 \mathrm{M})$. Proses hidrolisis asam dilakukan untuk mengubah selulosa dalam biji buah nangka masak yang berupa pati sebesar $36,7 \%$ menjadi glukosa. kadar glukosa terbanyak hasil hidrolisis dicapai pada saat konsentrasi larutan $\mathrm{H}_{2} \mathrm{SO}_{4} \quad 0,5 \mathrm{M}$. Dalam proses hidrolisis gugus $\mathrm{H}^{+}$dari $\mathrm{H}_{2} \mathrm{SO}_{4}$ akan mengubah gugus pati dari biji nangka menjadi gugus radikal bebas. Gugus radikal bebas yang kemudian akan berikatan dengan gugus $\mathrm{OH}^{-}$dari air dan bereaksi pada suhu $100^{\circ} \mathrm{C}$ selama 1 jam yang akan menghasilkan glukosa. Pada saat konsentrasi larutan $\mathrm{H}_{2} \mathrm{SO}_{4} \quad 0,1 \quad \mathrm{M}$ kebutuhan $\mathrm{H}^{+}$dari $\mathrm{H}_{2} \mathrm{SO}_{4}$ belum mencukupi sehingga tidak banyak terbentuk gugus radikal bebas dari pati biji buah nangka dan glukosa yang dihasilkan belum maksimal.
Penambahan konsentrasi larutan $\mathrm{H}_{2} \mathrm{SO}_{4}$ akan terbentuk lebih banyak gugus radikal bebas, tetapi penambahan konsentrasi larutan $\mathrm{H}_{2} \mathrm{SO}_{4}$ menyebabkan semakin sedikit air dalam komposisi larutan hidrolisis.

Sehingga kebutuhan $\mathrm{OH}^{-}$sebagai pengikat radikal bebas berkurang dan glukosa yang dihasilkan semakin sedikit Dengan demikian konsentrasi asam yang paling optimum saat reaksi hidrolisis untuk menghidrolisis pati dari biji nangka menjadi glukosa yang terbanyak adalah 1 M. Semakin tingginya konsentrasi glukosa maka bioetanol yang akan terbentuk akan semakin besar pula karena bahan yang akan difermentasi menjadi bioetanol adalah glukosa. Sehingga konsentrasi larutan $\mathrm{H}_{2} \mathrm{SO}_{4}$ sebesar 1 M inilah yang digunakan untuk menghidrolisis biji buah nangka sebelum dilakukan tahap selanjutnya yaitu fermentasi dengan variabel lama waktu fermentasi.

Hasil penelitian menunjukkan bahwa kadar glukosa tertinggi yang diperoleh yaitu pada konsentrasi $\mathrm{H}_{2} \mathrm{SO}_{4} \quad 0,1 \mathrm{M}$ sebesar 4,17\%, $\mathrm{H}_{2} \mathrm{SO}_{4}$ 0,5 $\mathrm{M}$ sebesar 5,35\% dan konsentrasi $\mathrm{H}_{2} \mathrm{SO}_{4} 1 \mathrm{M}$ sebesar 7,06\% untuk suhu $60^{\circ} \mathrm{C}$ dalam 30 menit (dapat dilihat pada tabel 1). Untuk suhu $60^{\circ} \mathrm{C}$ 
Produksi Bioetanol Dari Biji Buah Nangka Melalui Proses Hidrolisis Asam Sulfat Dan Fermentasi

selama 30 menit didapatkan kadar glukosa sebesar 4,61\%, untuk 60 menit 11,67 dan untuk 90 menit $4,72 \%$ (dapat dilihat pada table 2). Suhu hidrolisis $80^{\circ} \mathrm{C}$ selama 1 jam sebesar $56,71 \%$, suhu hidrolisis $100^{\circ} \mathrm{C}$ sebesar $13,44 \%$ dan suhu hidrolisis $120^{\circ} \mathrm{C}$ sebesar 3,99\% (dapat dilihat pada table 3). Jadi waktu hidrolisis yang paling baik digunakan adalah pada suhu $100^{\circ} \mathrm{C}$ selama 60 menit dengan konsentrasi $\mathrm{H}_{2} \mathrm{SO}_{4} 1 \mathrm{M}$.

Analisis kuantitatif untuk gula dilakukan dengan metode Luff schoorl. Metode ini didasarkan pada peristiwa tereduksinya kupri oksida menjadi kupro oksida, karena adanya gula reduksi. Reagen yang digunakan adalah larutan luff schoorl yang merupakan campuran kupri sulfat, natrium karbonat dan asam sitrat. Monosakarida yang terbentuk ditambahkan dengan larutan luff schoorl sebanyak $25 \mathrm{ml}$ lalu didihkan selama 10 menit. Setelah itu didinginkan dan ditambahkan KI. Kupri oksida berfungsi sebagai oksidator yang dengan adanya gula reduksi maka kupri oksida berubah menjadi kupro oksida. Kupro oksida dalam reaksi ini akan membebaskan lod dari garam KI, dimana banyaknya iod yang dibebaskan ekuivalen dengan kupro oksida. Banyaknya iod yang bebas dapat diketahui dengan titrasi menggunakan natrium tio sulfat dengan menggunakan indikator kanji.

Pada penelitian yang dilakukan, bietanol dibuat dengan memfermentasi serbuk biji buah nangka (Artocarpus heterophyllus) pada $\mathrm{pH} 5$ dengan variasi lama fermentasi 1 hari, 2 hari, 3 hari, 4 hari, 5 hari, 6 hari dan 7 hari.

Pada fermentasi ini digunakan khamir jenis Saccharomyces cerevisiae yang bersifat fermentatif yaitu dapat menfermentasi gula menjadi bioetanol pada keadaan anerob (tanpa udara) sedang jika terdapat udara maka khamir ini akan bersifat oksidatif yaitu mengoksidasi gula menjadi karbondioksida dan air.

Biji buah nangka (Artocarpus heterophyllus) yang telah dihidrolisis dan dihitung kadar glukosa, diatur $\mathrm{pH}$ nya pada pH 5 kemudian ditambahkan Sacharomyces cereviseae (fermipan) $10 \%$ dan difermentasi selama 1 hari, 2 hari, 3 hari, 4 hari, 5 hari, 6 hari dan 7 hari pada suhu kamar. Fermentasi berlangsung secara anaerob, diamana Erlenmeyer (fermentor) tempat fermentasi ditutup dengan sumbat karet yang diberi lubang kemudian pada lubang tersebut diberi selang dan ujung selang yang lainnya dicelup pada air sehingga udara dari luar tidak dapat masuk dan gas yang dihasilkan 
Produksi Bioetanol Dari Biji Buah Nangka Melalui Proses Hidrolisis Asam Sulfat Dan Fermentasi

dapat dikeluarkan melalui selang tersebut. Pada saat fermentasi berlangsung terjadi gelembunggelembung gas pada air yang keluar melalui selang yang ujungnya dihubungkan dengan botol fermentor, hal ini menunjukkan bahwa telah terjadi proses fermentasi yang ditandai dengan terbentuknya gas karbondioksida.

Sampel yang telah difermentasi didestilasi menggunakan alat destilasi sederhana, dimana proses ini dimaksudkan untuk memisahkan campuran antara air dan alkohol berdasarkan perbedaan titik didih yang nyata.

Hasil penelitian menunjukkan dengan menggunakan metode indeks bias dihasilkan nilai indeks bias pada hari 1 , hari 2 , hari 3 , hari 4 , hari 5 , hari 6 dan hari ke 7 dengan nilai indeks bias masing-masing 1,3382; 1,3386; 1,$3391 ; 1,3312 ; 1,3409 ; 1,3406$ dan 1,3397 (dapat dilihat pada gambar kurva 1). Gambar kurva tersebut memperlihatkan bahwa pada hari pertama bioetanol yang terbentuk masih sedikit. Hal ini disebabkan karena mikroorganisme (khamir) belum aktif (fase awal) sehingga laju pertumbuhannya rendah yang menyebabkan produk bioetanol yang dihasilkan relative sedikit.
Kadar bioetanol tertinggi dicapai pada waktu fermentasi 4 hari dengan kadar alkohol 13,19\% (dapat dilihat pada gambar kurva 2). Pada kurva tersebut dapat dilihat bahwa pada waktu fermentasi 4 hari diperoleh kadar bioetanol tertinggi. Hal ini disebabkan pada kondisi tersebut mikroorganisme bekerja dengan sempurna dimana laju pertumbuhannya mencapai maksimum sehingga bioetanol yang dihasilkan lebih tinggi. Sedang pada waktu fermentasi selanjutnya produk dan kadar bioetanol yang dihasilkan menurun yang disebabkan oleh keaktifan mikroorganisme mulai menurun artinya bahwa sel-sel mikroorganisme untuk menghasilkan enzim sebagai biokatalis untuk mengkonversi substrat menjadi bioetanol sudah mulai berkurang atau mengalami fase kematian.

Analisis sampel dari hasil indeks bias tertinggi dilanjutkan dengan alat kromatografi gas. Sampel sebanyak $0,2 \mu \mathrm{l}$ diinjeksikan ke dalam injector dari kromatografi gas pada suhu injektor $100^{\circ} \mathrm{C}$ dengan suhu kolom $70^{\circ} \mathrm{C}$, dimana respon detector digambarkan dalam perekam berdasarkan beda potensial dalam bentuk plot voltase dengan waktu, sehingga menghasilkan suatu 
Produksi Bioetanol Dari Biji Buah Nangka Melalui Proses Hidrolisis Asam Sulfat Dan Fermentasi

kromatogram dengan waktu retensi dan luas puncak bioetanol. Dari data tersebut dapat dihitung kadar bioetanol dengan membandingkan luas puncak bioetanol dalam sampel dengan luas puncak alkohol standar (etanol 99,98\%).

\section{KESIMPULAN}

Berdasarkan hasil penelitian dapat disimpulkan bahwa kadar bioetanol dari biji buah nangka (Artocarpus heterophyllus) dengan proses hidrolisis asam sulfat $1 \mathrm{M}$ pada suhu $100^{\circ} \mathrm{C}$ selama 1 jam berlangsung optimum pada hari ke 4 dengan kadar sebesar $13,19 \%$.

\section{DAFTAR PUSTAKA}

Heyne, K., 1987, Tumbuhan Berguna Indonesia Jilid II, Badan Litbang Kehutanan, Jakarta

Said, Gumbiro. 1987. Bioindustri Penerapan Teknologi
Fermentasi Edisi 1. Mediatama Sarana Perkasa, Jakarta

Anonim. 2005. Pembuatan Bioetanol. Skripsi Program Studi Kimia FMIPA Universitas Sumatra Utara,Medan.

Fessenden, R. J. dan Fessenden, J. S. 1997. Dasar- Dasar Kimia Organik. Binarupa Aksara, Jakarta.

Khamdiyah, N. 2010. Pembuatan Etanol dari Alga Merah Jenis Eucheuma spinosum Dengan Sakarifikasi dan Tanpa Sakarifikasi Pada Variasi Lama Fermentasi. Skripsi tidak diterbitkan, Fakultas Sains dan Teknologi Universitas Islam Negeri Maulana Malik Ibrahim, Malang.

Rohman, Abdul. 2009, Kromatografi Untuk Analisis Obat : Graha Ilmu, Yogyakarta

Hairani, R. 2007. Tanaman Jagung Sebagai Bahan Bio-fuel. http://www.macklin-tmip unpad.net/Biofuel/Jagung/Pati.p df, diakses pada tanggal 24 februari 2011 